\title{
Cavernous Hemangioma of the Small Bowel Presenting with Occult Obscure Gastrointestinal Bleeding
}

\author{
Emad Suliman Aljahdli
}

\begin{abstract}
This article is representing a 70 year-old woman with chronic iron deficiency anemia secondary to small bowel cavernous hemangioma.
\end{abstract}

Keywords: small bowel bleeding, cavernous hemangioma, occult gastrointestinal bleeding

A 70-year-old female was referred to our institution for further evaluation of chronic iron deficiency anemia with hematocrit of $32.8 \%$ and guaiac positive brown stools. Patient had no history of dysphagia, abdominal pain, weight loss, nausea, vomiting, or blood in the stool. She underwent upper endoscopy and colonoscopy that were unrevealing. Subsequently she underwent capsule endoscopy that showed a non-bleeding, ulcerated mass versus polyp in the jejunum. The patient then underwent CAT scan of abdomen and pelvis showing polypoid lesions in the mid-jejunum (Figure 1)

The findings led us to perform antegrade spiral enteroscopy, which showed a non-obstrcuting, protruding bluish and ulcerated lesions in the jejunum. The lesions were actively oozing blood (Figure 2). Given their atypical appearance, a decision was made to biopsy them and india ink was place at the site for future recognition.

The biopsies were unrevealing showing only normal small bowel mucosa. The patient was then referred to surgery for potentially malignant small bowel tumor. In the operating room, the endoscopically injected india ink was noted approximately $5 \mathrm{~cm}$ distal to the ligament of Trietz. The small bowel was run from the from the ligament of Treitz to the cecum and no other lesions were noted. The surgically resected lesion was approximately $8 \mathrm{~cm}$ long (Figure 3 ). The patent had an uneventful recovery and was discharged home in 5 days.

Final pathology showed large blood-filled sinuses lined by multiple layers of endothelial cells. Findings were consistent with cavernous hemangioma of the small bowel (Figure 4).
Gastrointestinal hemangiomas are uncommon benign vascular tumors that may occur anywhere in the gastrointestinal tract as single or multiple lesions. They are also seen in Hereditary Hemorrhagic Telangiectasia, Maffucci's syndrome, Klippel-Trenaunay syndrome, and Blue Rubber Bleb Nevus syndrome. Bleeding is the most common clinical presentation and can be insidious or massive and life-threatening. Patients may also present with abdominal pain, mechanical bowel obstruction, or perforation. Small bowel is the most common site of gastrointestinal hemangiomas. Colon is the second most common site. Histologically, they are classified into capillary hemangiomas with proliferation of small capillaries composed of a thin-walled, blood filled specs lined by endothelial cells and cavernous hemangiomas with large blood-filled sinuses lined by a single or multiple layers of endothelial cells.

\section{References}

[1] Gastrointestinal Hemangiomas: Imaging findings with pathologic in pediatric and adult patients. Angela D.Levy, Robert M. Abbott, Charles, A. Rohrman, Jr. , Aletta Ann Frazier. AJR:177, November 2001

[2] Dachman AH, Ros PR, Shekita KM, Buck JL, Olmsted WW, Hinton CB. Colorectal hemangioma: radiologic findings, Radiology 1988

[3] Bank ER, Hernandez RJ, Byrne WJ, Gatrointestinal hemangiomatosis in children; demonstration with CT. Radiology 1987; 165;657-658 
International Journal of Science and Research (IJSR)

ISSN (Online): 2319-7064

Index Copernicus Value (2013): 6.14 | Impact Factor (2014): 5.611

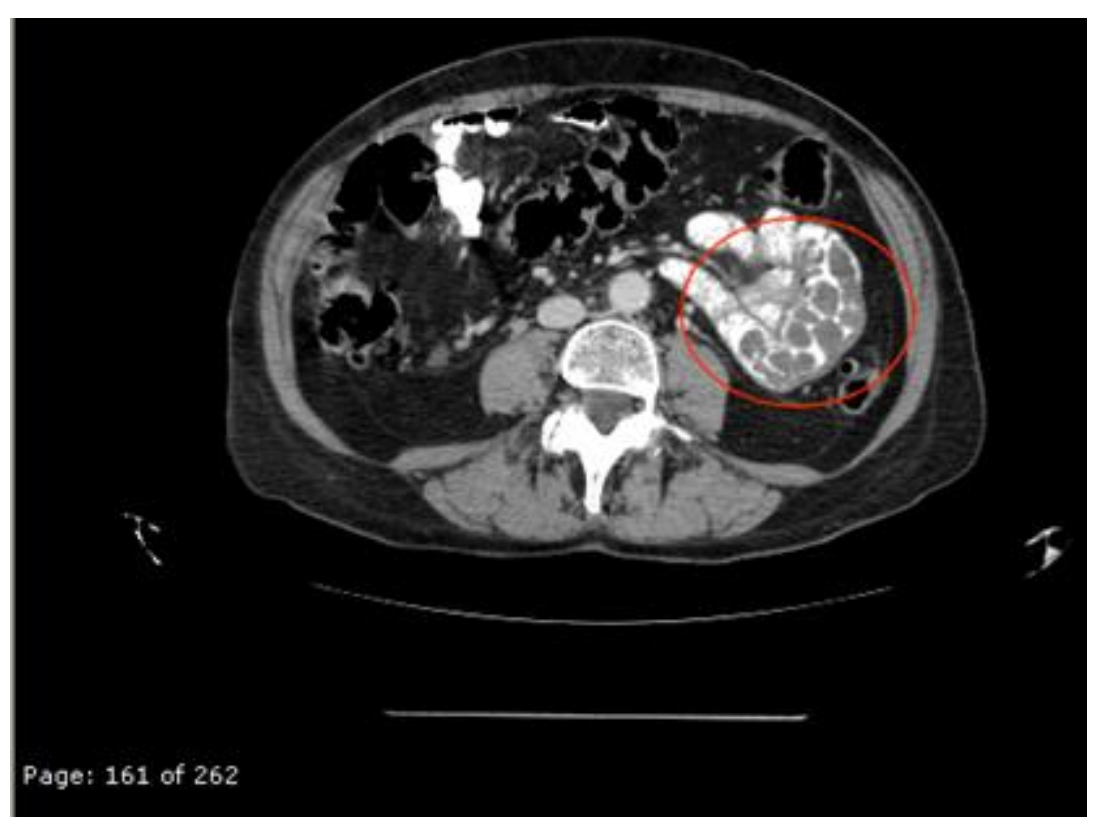

Figure 1

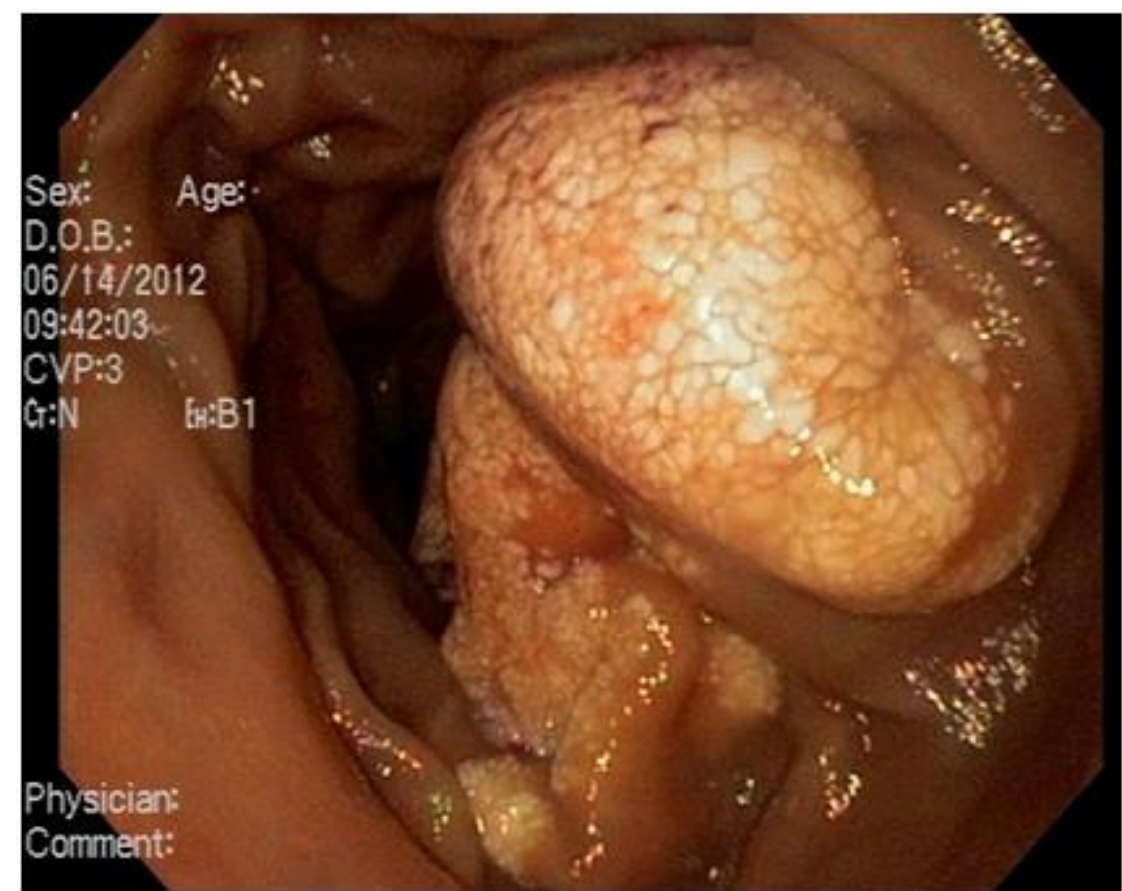

Figure 2

Volume 4 Issue 11, November 2015 www.ijsr.net 
International Journal of Science and Research (IJSR)

ISSN (Online): 2319-7064

Index Copernicus Value (2013): 6.14 | Impact Factor (2014): 5.611

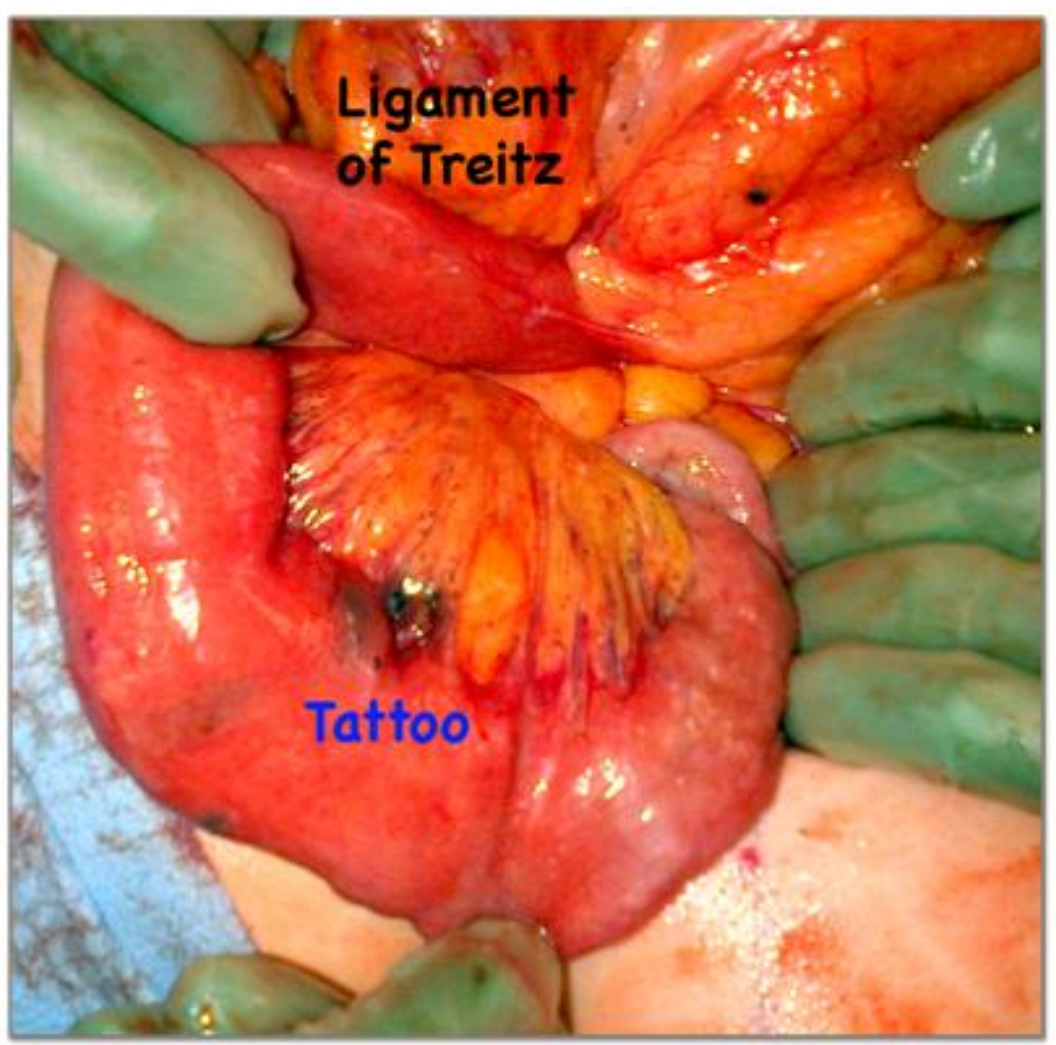

Figure 4

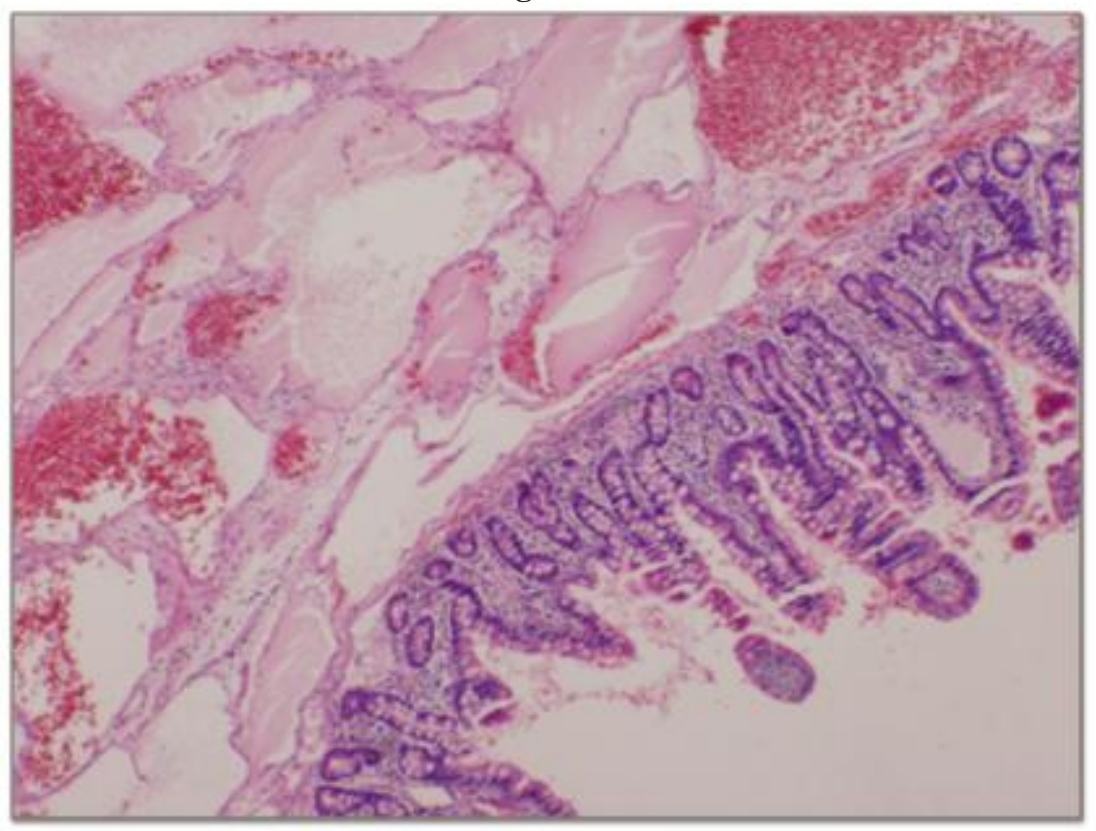

Figure 5

Volume 4 Issue 11, November 2015 www.ijsr.net 